\title{
Actividad financiera en el Estado constitucional: los ingresos producto de la gestión del patrimonio público en Colombia, Venezuela, Ecuador y Bolivia
}

\author{
Gabriel Santiago Galán Melo*
}

\section{RESUMEN}

Este ensayo trata de los ingresos fiscales producto de la gestión del patrimonio público como una manifestación cierta de la actividad financiera en el Estado constitucional (en Colombia, Venezuela, Ecuador y Bolivia) que busca (no exclusivamente a través de este mecanismo) procurarse los recursos económicos indispensables para financiar el gasto público; dado que el mismo, innegablemente, fue configurado jurídica e institucionalmente para que cumpla determinadas finalidades que satisfacen las necesidades comunes del colectivo gobernado, contenidas expresamente en el texto magno de la Constitución. La finalidad que este trabajo persigue es aportar al desarrollo del estudio de las normas constitucionales del derecho financiero público.

Palabras Clave: Estado del bienestar, actividad financiera, ingresos fiscales, patrimonio público.

\section{ABSTRACT}

This paper studies the tax revenue from the management of state assets. Such income is the result of the government financial activity in the constitutional state (of Colombia, Venezuela, Ecuador and Bolivia). The government seeks this income, among others, ensuring the necessary financial resources to finance public spending, since the state has an obligation to fulfill the purposes outlined in the Constitution. The aim of this essay is to contribute to the development of the study of constitutional rules of public finance law.

KEYWORDS: Welfare state, financial activity, tax revenues, public assets.

* $\quad$ Presidente del Instituto Ecuatoriano de Derecho Tributario (IEDT). 


\title{
LA EXTRAFISCALIDAD Y LA MOTIVACIÓN QUE APUNTALÓ POLÍTICAS PÚBLICAS A FAVOR DEL AMBIENTE
}

\author{
raíz de la asimilación general del Estado del bienestar, ${ }^{1}$ a partir del siglo $\mathrm{XX},{ }^{2}$ \\ A resulta prácticamente indispensable la intervención del Estado en la economía. ${ }^{3}$
} Se espera de aquel la promoción e imposición de un sistema adecuado de normas e instituciones con contenido y/o afectación económica que garanticen el ejercicio pleno de los derechos constitucionales de los individuos y colectivos que conforman el tejido social del estado. ${ }^{4}$ La gran depresión (1929-1939) y la segunda guerra mundial (1939-1945) evidenciaron dos necesidades: la de replantear la configuración de los sistemas económicos de libre mercado o laissez-faire ${ }^{5}$ y la de promover sistemas complejos caracterizados por la ineludible intervención del Estado y de sus instituciones públicas de gobierno en ese mismo mercado, ${ }^{6}$ a fin de asegurar un espacio libre de plena competencia, sin desviaciones ni externalidades.

1. Vid. Claus Offe, Contradicciones en el Estado de bienestar (Madrid: Alianza, 1990), 135-50.

2. Offe sostiene que, históricamente el estado del bienestar es el resultado combinado de diversos factores y que, las fuerzas más importantes que abogaron en su favor y otorgaron esquemas más y más amplios de seguro obligatorio, leyes sobre protección del trabajo, salario mínimo, expansión de servicios sanitarios y educativos y alojamientos estatalmente subvencionados, así como el reconocimiento de los sindicatos como representantes económicos y políticos legítimos del trabajo fueron el reformismo socialdemócrata, el socialismo cristiano, las élites políticas y económicas conservadoras ilustradas y los grandes sindicatos industriales. Cfr. Offe, Contradicciones en el Estado de Bienestar, 136.

3. La intervención y participación estatal en el mercado económico se consolidó con el reconocimiento y admisión generalizada del estado social y democrático de derecho, estado de bienestar o welfare state (Wohlfahrtsstaat) en los textos constitucionales contemporáneos. Este modelo superó la concepción económica clásica del Estado liberal decimonónico, de la no intervención o intervención mínima del Estado en la economía. Cfr. Klaus Tipke, Moral tributaria del Estado y de los contribuyentes (Madrid: Marcial Pons, 2002), 33-4; cfr. Luigi Ferrajoli, "Estado Social y Estado de Derecho”, en Víctor Abramovich, María José Añón y Christián Courtis, comp., Derechos Sociales. Instrucciones de uso (México: DJC, 2003), 11-3; cfr. José Roldán Xopa, Constitución y Mercado (México: Porrúa, 2004), 82-4; cfr. Javier Pérez Royo, Curso de Derecho Constitucional, 12a. ed. (Madrid: Marcial Pons, 2010), 145-6.

4. Vid. Ferrajoli, "Estado social y Estado de Derecho", 12 y 20-1.

5. "Laissez faire et laissez passer, le monde va de lui même", es una expresión francesa que significa: "dejad hacer, dejad pasar, el mundo va solo", con la cual se identifica al modelo de libre mercado e intervención mínima del Estado en la economía. En particular se la vincula a la teoría económica de la mano invisible de Adam Smith, y de modo general, a los aportes teórico-económicos de Smith, Ricardo y Marshall.

6. John Maynard Keynes justificó científicamente el intervencionismo moderado del Estado en la economía. Cfr. José Paschoal Rossetti, Introducción a la Economía. Enfoque latinoamericano (México: Harla S.A., Harper \& Row Latinoamericana, s. f.), 67-71. Offe sostiene que fue a la luz de la doctrina keynesiana de la planificación económica que el estado del bienestar llegó a concebirse no tanto como una carga impuesta a la economía, sino como un estabilizador interno de tipo económico y político, que ayudaba a regenerar las fuerzas del crecimiento económico y evitaba que la economía cayese en espirales descendientes hacia profundas recesiones. Cfr. Offe, Contradicciones en el Estado de Bienestar, 137. Troya Jaramillo advierte que la intervención del Estado en la economía, en los estados constitucionales actuales, se concreta a través de la función de planificación. Cfr. José 
Tales necesidades y sus posibles soluciones se han ido materializando en los textos fundamentales de los diversos Estados a partir de las constituciones de México de $1917^{7}$ y de Weimar de 1919. ${ }^{8}$ De manera general, los Estados han buscado declarar reglas esenciales de un sistema económico particular dentro de su configuración institucional $1^{9}$ y describir el conjunto de principios y normas que configurarían dicho sistema, entre ellas, las que prevean las funciones, finalidades y límites del estado en su rol dentro de la economía y las herramientas asignadas a aquel para garantizar el goce efectivo de los derechos reconocidos a sus ciudadanos. ${ }^{10}$ Por ello, hoy en día en Latinoamérica se ha generalizado el interés por estudiar las constituciones económicas de los estados, ${ }^{11}$ pero se lo viene haciendo -con aparente exclusividad- desde el matiz del derecho constitucional económico. Poco han dicho los hacendistas a pesar de que el objeto de estudio de la hacienda pública, sustancialmente, es la actividad financiera del Estado; es decir, el conjunto de acciones que ejecuta institucional, normativa y técnicamente a fin de obtener los recursos suficientes para el sostenimiento del gasto público destinado al cumplimiento de sus fines; la que, inevitablemente delimita el rol del estado dentro de la economía. ${ }^{12}$

Por lo que, el objetivo ulterior de este ensayo es aportar al estudio de la constitución económica desde la perspectiva de la hacienda pública. Para ello, se analizarán las disposiciones fundamentales de las nuevas constituciones andinas (Colombia, Venezuela, Ecuador y Bolivia) en torno a un tópico en particular: los ingresos producto del patrimonio público, para lo cual previamente debe justificarse la necesidad de tales ingresos en torno a la actividad financiera del estado en su configuración contemporánea y conceptualizar lo que debe entenderse por ingresos fiscales.

Vicente Troya Jaramillo, "El modelo económico, financiero y tributario de la Constitución de 2008”, en Santiago Andrade, Agustín Grijalva y Claudia Storini, edit., La nueva Constitución del Ecuador. Estado, derechos e instituciones (Quito: UASB/CEN, 2009), 317-9.

7. Vid. Constitución Política de los Estados Unidos Mexicanos (1917), Diario Oficial de 5 de febrero de 1917, artículos 25, 27-8 y 123 .

8. Vid. "Constitución de Weimar (1919)", en Textos constitucionales españoles y extranjeros (Zaragoza: Athenaeum, 1930), artículos 119-22, 142-50 y 151-65.

9. Vid. Ignacio María de Lojendio, "Derecho Constitucional Económico", en Luis Sánchez Agesta, coord., Constitución y Economía. La Ordenación del Sistema Económico en las Constituciones Occidentales (Madrid: Editorial Revista de Derecho Privado/Editoriales de Derecho Reunidas, 1977), 82 y s.

10. Vid. Julio César Trujillo Vásquez, "La Constitución económica, más allá del neoliberalismo", Foro: Revista de Derecho, No. 7 (2007): 112. Disponible en 〈http://repositorio.uasb.edu.ec/bitstream/10644/1658/1/RF-07-TCTrujillo.pdf>. Consulta: abril de 2016.

11. Cfr. Allan R. Brewer-Carías, "Reflexiones sobre la constitución económica", en Sebastián Martín-Retortillo, coord., Estudios sobre la Constitución española. Homenaje al profesor Eduardo García de Enterría, tomo V (Madrid: Civitas, 1991), 3840.

12. Vid. Klaus Vogel, "La Hacienda pública y el Derecho constitucional”, Revista Hacienda Pública española, No. 59 (1987): 15-23. 


\section{LA ACTIVIDAD FINANCIERA DEL ESTADO}

El Estado -en la acepción general moderna (decimonónica) que superó la organización política medieval- es aquella unidad de dominación, claramente delimitada en lo personal y territorial, independiente (interna y externamente), que actúa continuamente y con medios de poder propios..$^{13}$ Cosculluela Montaner sostiene que el origen de dicha acepción (la del Estado moderno) provino de un proceso histórico ideológico en el que sobresalieron los lineamientos teóricos de tres autores en particular: 1 . Maquiavelo, ${ }^{14}$ quien decantó la desvinculación del poder político del religioso (a través del estado) $;{ }^{15}$. Bodino, ${ }^{16}$ que cimentó el concepto de soberanía caracterizándola como aquel poder absoluto y perpetuo de una república; y, 3. Hobbes,${ }^{17}$ que percibió, finalmente, al Estado como aquella organización social compleja y poderosa que ejerce, precisamente, su poder de dominación con una misión utilitarista para la propia sociedad gobernada. ${ }^{18}$ En conjunto, tales lineamientos, proyectaron por primera vez aquella entidad civil organizada al servicio de los titulares del poder institucionalizado en ella misma, la cual -en definitiva- se estableció como la Primera República Francesa. ${ }^{19}$

De manera que, desde la concepción primigenia del Estado moderno y hasta la actualidad, este debe y ha debido cumplir con ciertos fines vinculados a la sociedad que lo conforma; caso contrario, no hubiesen existido motivos o causas suficientes para concebirlo como una unidad de poder en ejercicio, circunscrita legítimamente a los intereses de los individuos que la reconocen como dominante. Al respecto, Sayagués Laso afirma que el Estado "es todo aquello que constituye la organización jurídica de la colectividad"; $; 0$ de modo tal que el dimensionamiento del estado solo puede ser percibido a través de la organización del poder (en persecución de ciertos fines),

13. Cfr. Hermann Heller, Teoría del Estado (México: Fondo de Cultura Económica, 1992), 141-3.

14. Vid. Nicolás Maquiavelo, El príncipe. Disponible en 〈http://www.ciudadoriental.com/elprincipe.pdf〉. Consulta: abril de 2016.

15. Heller sostiene que, Maquiavelo introdujo por primera ocasión el término: lo stato, para designar al nuevo estatus político que propone. En consecuencia ahí radicaría el origen de la construcción semántica moderna del término: estado. Cfr. Heller, Teoría del Estado, 170.

16. Jean Bodin, Los seis libros de la República, Pedro Bravo Gala, trad. (Madrid: Tecnos S.A., 1997), 142.

17. Vid. Thomas Hobbes, Leviatán o La materia, forma y poder de una República Eclesiástica y Civil (Bogotá: Skala, 1982), 144-317.

18. Cfr. Luis Cosculluela Montaner, Manual de Derecho administrativo. Parte general, 21a. ed. (Pamplona: Civitas/ Thomson Reuters/Aranzadi S.A., 2010), 21.

19. La Primera República Francesa fue proclamada el 21 de septiembre de 1792, fecha en la que el rey Luis XVI fue destituido de su cargo, finalizando así la monarquía francesa. Esta (la Primera República) duró un total de doce años hasta el establecimiento del Primer Imperio francés por parte de Napoleón Bonaparte en 1804.

20. Enrique Sayagués Laso, Tratado de Derecho administrativo (Montevideo: Martín Bianchi Altuna, 1959$), 157$. 
por intermedio del límite exclusivo de la juridicidad, la cual deviene del sentimiento implícito de cohesión armónica de un colectivo determinado. Por eso, cabe advertir asimismo en el desarrollo del modelo del Estado moderno, los aportes sustanciales de las nociones de soberanía popular acuñada por Rousseau, ${ }^{21}$ que dio cuenta final de los titulares del poder soberano: el pueblo, y de la división de poderes promovida originalmente por el Barón de Montesquieu, ${ }^{22}$ los cuales cimentaron precisamente los límites jurídicos del ejercicio del poder público.

Por ello, el Estado de derecho se ha caracterizado por cuatro principios jurídicos particulares, que en definitiva conforman -hasta el día de hoy-el mínimo de intereses comunes en una sociedad armónica, y que le sirvieron, a su vez, como límites implícitos jurídicos al ejercicio del poder originario constitutivo del mismo Estado; a saber: la soberanía popular, la teoría de la división de poderes, el principio de legalidad y el reconocimiento de los "derechos públicos subjetivos", ${ }^{23}$ que compilan, hoy en día, un grupo indeterminado de derechos fundamentales (individuales y colectivos), vinculados a la dignidad de la persona humana ${ }^{24}$ los cuales, a su vez, han legitimado los fines ulteriores del Estado constituido.

Hobbes, por ejemplo, sostuvo que el fin primordial del Estado es la seguridad (interna y externa): "la causa final, fin o designio de los hombres (que naturalmente aman la libertad y el dominio sobre lo demás) al introducir esta restricción sobre sí mismos (en la que los vemos vivir formando Estados) es el cuidado de su propia conservación, y por añadidura, el logro de una vida más armónica"; ${ }^{25}$ el cual configuró un Estado liberal-mínimo que aparentemente patrocinaba -obligado de manera negativa ${ }^{26} \mathrm{el}$ libre desarrollo de la personalidad del individuo (ciudadano).

21. Vid. Jean-Jacques Rousseau, El contrato social o principios del derecho político, capítulo VII. Disponible en 〈http://www. biblioteca.org.ar/libros/70390.pdf〉. Consulta: abril de 2016.

22. Vid. Charles Louis Secondat, señor de la Bréde y Barón de Montesquieu, El Espíritu de las Leyes (Madrid: Librería General de Victoriano Suárez, 1906), 246-9 y 251-70. Disponible en 〈http:// fama2.us.es/fde/ocr/2006/ espirituDeLasLeyesT1.pdf). Consulta: abril de 2016.

23. Cosculluela Montaner, Manual de Derecho administrativo. Parte general, 24; vid. Humberto Nogueira Alcalá, Teoría y dogmática de los derechos fundamentales (México: Universidad Nacional Autónoma de México, 2003), 55-8. Disponible en 〈http://biblio.juridicas.unam.mx/libros/3/1094/4.pdf〉. Consulta: mayo de 2016.

24. Vid. Cosculluela Montaner, ibíd., 22-5; vid. Rafael Oyarte Martínez, Curso de Derecho constitucional, tomo I (Quito: Fundación Andrade \& Asociados/Fondo Editorial, 2007), 112-20.

25. Hobbes, Leviatán o La materia, forma y poder de una República Eclesiástica y Civil, 144.

26. Abramovich y Courtis sostienen que la distinción entre obligaciones negativas y positivas del Estado tiene fundamento en una visión totalmente sesgada y naturalista del funcionamiento del mismo, la cual coincide con la posición decimonónica del Estado liberal-mínimo, garante de la justicia, seguridad y defensa, pero que, inclusive para los pensadores más clásicos de la economía política como Adam Smith y David Ricardo, ha resultado obvia la interrelación de las supuestas obligaciones negativas del Estado y una larga serie de obligaciones positivas, en especial en materia de garantía de la libertad de comercio, vinculadas con el mantenimiento de las instituciones políticas, judiciales, de seguridad y defensa, necesarias como condición para el ejercicio de la libertad individual. Cfr. Víctor Abramovich y Christian Courtis, "Hacia la exigibilidad de los derechos económicos, sociales y 
Tal designio, la seguridad, había sido perseguido ya por el Estado monárquicoabsolutista pero con un contenido diferente. A partir de la Revolución francesa el fin del Estado fue la seguridad de los ciudadanos, ya no la seguridad del reino inmerso en un juego permanente de expansión y sometimiento, sino la conservación del individuo en una lucha inquebrantable de defensa por lo propio, promoviendo la protección de la propiedad -en discurso al menos- de todos los ciudadanos y no exclusivamente de uno: el príncipe. Sin embargo, la proyección del derecho a la propiedad privada, que estructuró a lo largo del siglo XIX una sociedad capitalista, lejos de superar el conflicto por el poder que causó en último término la toma de la Bastilla en 1789, ahondó socialmente la diferencia entre los pocos poseedores de las mercancías (el capital) y los muchos titulares de la fuerza de trabajo (el trabajo), configurándose estructuralmente un nuevo grupo hegemónico: el capital, que obligó la reacción de aquel que no lo era y había sido sometido arbitrariamente a aquel: el trabajo. Marx, en su crítica a la economía política de aquella época, describe dicha tensión de la siguiente manera:

La economía política procura, por principio, mantener en pie la más agradable de las confusiones entre la propiedad privada que se funda en el trabajo personal y la propiedad privada capitalista -diametralmente contrapuesta-, que se funda en el aniquilamiento de la primera. En el occidente de Europa, patria de la economía política, el proceso de la acumulación originaria se ha consumado en mayor o menor medida. En esta región, o el modo capitalista de producción ha sometido directamente la producción nacional en su totalidad, o, allí donde las condiciones aún no están desarrolladas, por lo menos controla indirectamente las capas sociales que siguen vegetando a su lado, capas degenerescentes que corresponden al modo de producción anticuado. El economista aplica a este mundo acabado del capital las nociones jurídicas y de propiedad vigentes en el mundo precapitalista, y lo hace con un celo tanto más ansioso y con tanta mayor unción, cuanto más duro es el choque entre su ideología y los hechos. ${ }^{27}$

Por lo que, concluida la segunda guerra mundial, que por sus efectos visibilizó con notoriedad dicho desacuerdo entre el capital y el trabajo, se manifestó la necesidad de replantear el rol del estado en la economía. ${ }^{28}$ En tales condiciones, se conformó el

culturales. Estándares internacionales y criterios de aplicación ante los tribunales locales”, en Martín Abregú y Christian Courtis, edit., La aplicación de los tratados internacionales sobre derechos humanos por los tribunales locales (Buenos Aires: Ed. Del Puerto/CELS, 1997), 284-5.

27. Karl Marx, El Capital. Libro primero. El proceso de producción del capital, tomo 1, vol. 3 (México: Siglo XXI, 2005), 955.

28. Keynes sostuvo que los principales inconvenientes en la sociedad económica de aquel entonces fueron su incapacidad para procurar la ocupación plena y su arbitraria y desigual distribución de la riqueza y de los ingresos; ya que, bajo el sistema de laissez-faire nacional y el patrón oro internacional que fue el predominante en el siglo XIX no había medio disponible del que pudiera valerse el gobierno para mitigar la miseria económica al interior, excepto el de la competencia por los mercados, porque se desechaban todas las medidas que pudiesen ayudar los 
Estado del bienestar. Offe advierte, con notable recato, que el Estado del bienestar fue la principal fórmula pacificadora de las democracias capitalistas luego de la segunda guerra mundial; modelo que se caracterizó básicamente por: 1. la obligación explícita que tuvo que asumir el aparato estatal para suministrar asistencia y apoyo -en dinero o en especie- a los ciudadanos que sufrían necesidades y riesgos específicos característicos de la sociedad mercantil, que se proporcionaba en virtud de pretensiones legales otorgadas a los ciudadanos, y, 2. el reconocimiento del rol formal de los sindicatos tanto en la negociación colectiva como en la formación de los planes públicos. De este modo -firma dicho autor-, por intermedio del Estado del bienestar se limitó y mitigó el conflicto de clases, se equilibró la asimétrica relación de poder entre el capital y el trabajo, y se pudo superar las luchas paralizantes y contradicciones que constituyeron el rasgo más ostensible del capitalismo liberal. ${ }^{29}$

De ahí que Offe concluya, con prudente acierto, que el Estado del bienestar es una "solución política a contradicciones sociales". ${ }^{30}$ No obstante, dicha fórmula pacificadora aparentemente equilibrada ha sido objeto de constantes y severas críticas. Por una parte, los conservadores (cercanos al capital) justifican el desmonte del Estado del bienestar en torno a dos aseveraciones: 1 . el aparato estatal en este modelo impone una carga fiscal y normativa al capital que equivale a un desincentivo para la inversión, y, 2. el estado del bienestar garantiza pretensiones, títulos y posiciones de poder colectivo a trabajadores y sindicatos que equivalen a un desincentivo para el trabajo (con relación al trabajo presuntamente duro y productivo impuesto por las fuerzas mercantiles no reprimidas). ${ }^{31}$

En consecuencia, si se juntan ambos asertos -según lo manifestado- este modelo conduciría sencillamente "a una dinámica de crecimiento declinante y crecientes expectativas, de sobrecarga en la demanda económica (conocida como inflación) y a una sobrecarga en la demanda política (ingobernabilidad), que cada vez pueden satisfacerse menos por medio de la producción posible". ${ }^{32}$ Dicha apreciación resulta naturalmente exagerada..$^{33}$

estados de desocupación crónico o de subocupación intermitente, excepto las que servían para mejorar la balanza comercial en las partidas relativas a mercancías y servicios. Por ello concluye -entre otras-, por ejemplo, que el Estado tiene que ejercer una influencia orientadora sobre la propensión a consumir, a través de su sistema de impuestos, fijando la tasa de interés, y, quizá por otros medios. Cfr. John Maynard Keynes, Teoría general de la ocupación, el interés, y el dinero, Eduardo Hornedo, trad. (México: Editorial Muñoz, 1965), 328-37.

29. Cfr. Offe, Contradicciones en el Estado de Bienestar, 135-6.

30. Ibíd., 136.

31. Ibíd., 137-8.

32. Ibíd., 138.

33. Por ejemplo, la carga fiscal en los países escandinavos sobrepasa el 50\% del Producto Interno Bruto (PIB); y de ningún modo se podría concluir que estas cifras han detenido los niveles de producción de tales Estados. En realidad, los mismos mantienen niveles estables de crecimiento económico. Vid. Eurostat, Europe in figures. 
Por otra parte, los progresistas (cercanos al trabajo) califican al Estado del bienestar como ineficaz e ineficiente, represivo y responsable de un entendimiento (ideológico) falso de la realidad social y política dentro de la clase obrera. Afirman se trata simplemente de un instrumento para estabilizar y no para trasformar la sociedad capitalista; y advierten que el estado del bienestar no elimina las causas de los inconvenientes (falta de empleo y desigualdad) que presenta el modelo sino que sencillamente las compensa: ${ }^{34}$ "A despecho de las innegables ventajas en condiciones de vida de asalariados, la estructura institucional del Estado del bienestar ha hecho poco o nada por alterar la distribución de ingresos entre las dos clases principales que son el trabajo y el capital. La enorme maquinaria de redistribución no funciona en la dirección vertical sino en la horizontal, esto es, dentro de la clase de los asalariados" ${ }^{35}$

Sin embargo, el Estado del bienestar sigue firmemente engastado en el orden social ${ }^{36}$ de las sociedades capitalistas avanzadas, ${ }^{37}$ sujeto sí a correcciones pero es un

Eurostat yearbook 2012, 29-105. Disponible en «http://ec.europa.eu/eurostat/documents/ 3217494/5760825/KSCD-12-001-EN.PDF>. Consulta: abril de 2016; vid. Eurostat, Eurostat regional yearbook 2015, 125-61. Disponible en 〈http:/ec.europa.eu/eurostat/documents/3217494/7018888/KS-HA-15-001-EN-N.pdf/6f0d4095-5e7a4aab-af28-d255e2bcb395〉. Consulta: abril de 2016. Por otra parte, a partir de 1998, el gobierno francés impulsó la disminución de la jornada laboral de trabajo a 35 horas semanales y pese a ello, el porcentaje de individuos ocupados y el PIB no han dejado de incrementarse. Vid. INSEE, National Institute of Statistics and Economic Studies (Instituto Nacional de Estadísticas y Estudios Económicos de Francia), France in figures. Edition 2015, 12-5. Disponible en 〈http://www.insee.fr/fr/pdf/france-en-bref-2015.pdf〉. Consulta: abril de 2016. Por lo que, resultan imprecisas las aseveraciones realizadas por los críticos conservadores.

34. Cfr. Offe, Contradicciones en el Estado de Bienestar, 143-4.

35. Ibíd., 144.

36. En el trigésimo primer período de sesiones de la Comisión Económica para América Latina y el Caribe (CEPAL), en atención a los diferentes grados de intervención del Estado en el economía, se reconocieron tres modelos paradigmáticos de Estado del bienestar: el régimen liberal del bienestar (que minimiza el estado, individualiza los riesgos y fomenta las soluciones de mercado en el marco del manejo residual del riesgo), el régimen socialdemócrata de bienestar (que tiene una orientación universalista, igualitarista y comprometida con la noción de derechos) y el régimen conservador de bienestar (que se distingue por fuertes rasgos corporativistas). Cfr. Comisión Económica para América Latina y el Caribe (CEPAL), Naciones Unidas, La protección social de cara al futuro: acceso, financiamiento y solidaridad, trigésimo primer período de sesiones, Montevideo, del 20 al 24 de marzo de 2006,33 , recuadro I.2.

37. Giuliani Fonrouge señala que si en alguna materia se advierte una transformación fundamental en los conceptos, marcándose notables diferencias entre las finanzas clásicas y las finanzas modernas, ella corresponde al gasto público. Sostiene que ha variado el criterio de apreciación, que, de esencialmente cuantitativo, ha pasado a ser esencialmente cualitativo; e indica que, si se parte de la base establecida por Adam Smith y recogida por las finanzas denominadas clásicas, el Estado debía restringir su acción a las funciones indispensables para la seguridad y existencia de la nación por lo que la actividad estatal no es económicamente productiva: el Estado consume y no produce que es la posición generalmente llamada del Estado gendarme o del laissez faire que Duverger llama Estado-consumidor. Para la moderna tendencia del Estado no es un mero consumidor sino un redistribuidor de la riqueza. En este sentido cabe mencionar la teoría del filtro del profesor Laufenburger según el cual el presupuesto actúa como un filtro económico, procede a modo de una bomba que aspira rentas y luego como impelente de ellas mediante los gastos públicos que las expande sobre la economía ofreciendo nuevas posibilidades de consumo e inversión. Nos hallamos en presencia pues de una nueva concepción del gasto público como consecuencia de las funciones que por fuerza de las circunstancias han debido asumir el estado en especial en lo que ha dado por 
modelo que parece no se verá fácilmente reemplazado por una alternativa conservadora o progresista, a pesar de las múltiples críticas propuestas, ${ }^{38}$ por lo que la configuración base de los estados constitucionales en Colombia, Venezuela, Ecuador y Bolivia sigue replicando las nociones primigenias del Estado del bienestar, al menos dentro de su ordenación financiera: el Estado se proyecta como una solución pacífica a fuertes contradicciones sociales, debiendo por un lado, garantizar un mercado de plena y libre competencia, y, por otro, la justa redistribución de la riqueza, ambos en torno a los valores fundacionales de la libertad, la igualdad y la solidaridad.

Ahora bien, el objetivo de la primera parte de este texto no es determinar la concepción ni los elementos constitutivos del Estado (menos aún del Estado del bienestar), sino el describir la actividad financiera del mismo en la realización de sus fines, a efecto de evidenciar la necesidad pública de generar ingresos fiscales para satisfacer los intereses del colectivo cohesionado bajo su dominio. Por lo que, previamente, se ha puesto de manifiesto, a través de la concepción jurídica más básica del Estado y de la caracterización política del Estado del bienestar, ${ }^{39}$ la obvia particularidad de que el poder político ha sido organizado jurídica e institucionalmente para que cumpla ciertas finalidades que satisfagan las necesidades comunes del colectivo gobernado. A dicho efecto debe precisarse que el Estado para realizar sus fines ejecuta una serie continuada de actos y actividades determinadas para lo cual requiere, asimismo, de medios suficientes e idóneos.

Fraga resume tales actos y actividades permanentes en tres categorías: 1. las facultades de policía (control) o de coacción que se concretan en las medidas forzosas que impone el estado contemporáneo a los particulares para el cumplimiento de ciertas obligaciones o para la limitación de algunos actos; 2. las facultades de fomento que engloban aquellas medidas que, sin hacer uso de las facultades de coacción, se dirigen a satisfacer indirectamente ciertas necesidades consideradas de carácter público, pro-

llamarse el welfare state, el estado de bienestar que corresponde a una economía en que la provisión de servicios estatales y pagos de transferencia (seguridad social) han alcanzado un elevado grados de desarrollo. Cfr. Carlos María Giuliani Fonrouge, Derecho financiero, tomo 1, 9a. ed. (Buenos Aires: La Ley, 2004), 185-7.

38. Cfr. Offe, Contradicciones en el Estado de bienestar, 147. Offe también menciona que existen ciertas alternativas propuestas por intelectuales y otras minorías, las que difícilmente desplazarán el modelo del Estado del bienestar. Refiere, por un lado el modelo neoliberal (neolaissez-faire) según el cual debe abolirse el estado del bienestar para producir un resurrección de la sociedad mercantil libre y armoniosa. Por otro lado, se propone un modelo en el que las funciones del Estado del bienestar deben ser asumidas por comunidades libertarias, igualitarias, y en buena medida autosuficientes, que trabajarían dentro de un marco altamente descentralizado y desburocratizado. Vid. Offe, Contradicciones en el Estado de Bienestar, 147.

39. La noción política del Estado del bienestar encuentra reflejo en la noción jurídica del Estado social de derecho, el cual no supone un modelo antitético del Estado de derecho; todo lo contrario, respeta los mismos principios esenciales pero ahonda en el principio democrático e incluye en el texto constitucional nuevos derechos sociales y la necesidad de la acción intervencionista del Estado. Vid. Cosculluela Montaner, Manual de Derecho administrativo. Parte general, 25-6. 
tegiendo o promoviendo las actividades de los particulares o de otros entes públicos (que directamente satisfacen tales necesidades); y 3. las facultades de servicio público y de seguridad social que comprenden aquellos mecanismos dirigidos a satisfacer necesidades generales por medio de prestaciones de carácter económico, cultural y asistencial. ${ }^{40}$ Obviamente, a fin de ejecutar dichas facultades, el Estado (como institución) tiene la inminente necesidad de obtener los recursos económicos suficientes (entre otros) que le permitan, efectivamente, realizar los fines para los cuales ha sido constituido y solventar eficientemente el gasto público que aquello ocasiona.

Al respecto, Troya Jaramillo indica que el Estado del bienestar para lograr el cumplimiento de sus fines, con el objeto de satisfacer las necesidades generales de la población, posee la potestad jurídica de obtener recursos públicos a través de la imposición de una serie de tributos; no obstante, reconoce asimismo que las erogaciones del estado son atendidas con ingresos tributarios y no tributarios. ${ }^{41}$ Giuliani Fonrouge distingue los recursos del Estado que provienen de la gestión de los bienes y de las actividades de aquel, de aquellos que resultan del ejercicio de los poderes inherentes a la soberanía o al poder de imperio. Entre los primeros ubica a aquellos producidos por los bienes del dominio público estatal o por las empresas y servicios públicos, y sitúa en los segundos, a los tributos, a las sanciones fiscales y al crédito público; ${ }^{42}$ todos ellos destinados finalmente al sostenimiento del gasto público (corriente y de inversión). Por su parte, Samuelson y Nordhaus afirman que:

En todos los países modernos, incluso en los que se basan principalmente en las fuerzas del mercado para asignar la mayoría de bienes y servicios, el Estado desempeña un importante papel en algunos sectores clave. Actualmente, fija el marco jurídico del mercado, regula el sistema financiero, fomenta la competencia y cuida de aquellos que no pueden valerse por sí mismos. ¿Cómo cumple sus responsabilidades económicas? No existe ningún secreto mágico. El Estado obtiene recursos por medio de los impuestos y utiliza sus votos monetarios para comprar bienes y servicios en el mercado. ${ }^{43}$

De modo que el Estado para cumplir sus fines necesita inevitablemente recursos económicos, los mismos que van encaminados al gasto público. Estos, se obtienen por medio de ingresos tributarios e ingresos no tributarios. Los primeros, resultado de la potestad pública de imponer tributos a los habitantes de un estado determinado (impuestos, tasas, contribuciones especiales de gasto y de mejoras, y exacciones pa-

40. Cfr. Gabino Fraga, Derecho administrativo (México: Porrúa S.A., 1990), 5.

41. Cfr. José Vicente Troya Jaramillo, Apuntes sobre la teoría de la tributación, material de lectura Maestría en Derecho, Universidad Andina Simón Bolívar, Quito, marzo de 2002, 1.

42. Cfr. Giuliani Fonrouge, Derecho financiero, 197.

43. Paul Samuelson y William Nordhaus, Economía, 14a. ed. (Madrid: McGraw-Hill, 1993), 386. 
rafiscales ${ }^{44}$ ); y los segundos, vinculados a la capacidad de aquel Estado para obtener ingresos por la adecuada gestión de su patrimonio o para obtener lícitamente cualquier otra fuente de financiamiento, pudiendo obligarse para con terceros en la restitución de los empréstitos que recibiese y en el pago de los intereses que estos llegaran a generar. De esto trata la actividad financiera del Estado: de la función que este desarrolla para procurarse los recursos económicos necesarios (suficientes) para financiar las erogaciones y gastos públicos, ${ }^{45}$ destinados a satisfacer las necesidades comunes del colectivo que lo conforma; buscando no solamente la obtención de ingresos, sino también la realización de aquellos gastos encaminados a la consecución de los fines del mismo estado, por intermedio de un presupuesto constitucional y legalmente aprobado.

Ferreiro Laptza afirma que:

Cuando el Estado y los demás entes públicos obtienen y utilizan medios dinerarios para realizar las tareas que la colectividad les encomienda están desarrollando una actividad que tradicionalmente se conoce con el nombre de actividad financiera. Tal actividad se caracteriza por el sujeto que la realiza (el Estado y demás entes públicos); por el objeto sobre el que recae (los ingresos y gastos públicos $[\ldots]$ y por su carácter instrumental. ${ }^{46}$

Villegas, por su parte, define la actividad financiera del Estado como aquel "conjunto de operaciones del Estado que tienen por objeto tanto la obtención de recursos como la realización de los gastos públicos necesarios para movilizar las funciones y los servicios públicos aptos para satisfacer las necesidades de la comunidad". ${ }^{47} \mathrm{De}$ manera que, la actividad financiera del Estado no es sino una actividad de medios y de fines. De medios, en tanto se preocupa por la generación de los recursos suficientes que le permitan financiar los servicios públicos y demás actividades del Estado; ${ }^{48} \mathrm{y}$ de fines, porque a través de aquella, como instrumento - a más del solo sostenimiento del gasto público-, se busca una justa y equitativa redistribución de los ingresos, la estabilidad del estado y su desarrollo. ${ }^{49}$

Por ello, Griziotti advierte que el requerimiento de recursos por parte del Estado se debe a la necesidad que tiene por cumplir con los fines para los cuales fue creado y

44. Vid. Juan José Ferreiro Lapatza, Curso de Derecho financiero español. Instituciones, 25a. ed. (Madrid: Marcial Pons, 2006), 332-55; vid. José Luis Pérez de Ayala y Eusebio González, Derecho tributario I (Salamanca: Plaza Universitaria Ediciones, 1994), 170-83.

45. Cfr. Manuel Matus Benavente, Finanzas públicas (Santiago de Chile: Editorial Jurídica de Chile, 1964 ), 107.

46. Ferreiro Lapatza, Curso de Derecho financiero español. Instituciones, 17.

47. Héctor Villegas, Manual de finanzas públicas (Buenos Aires: Depalma, 2000), 12.

48. Cfr. Guillermo Ahumada, Tratado de finanzas públicas, tomo 1, 4a. ed. (Buenos Aires: Plus Ultra, 1969$), 27$.

49. Vid. Dino Jarach, Finanzas públicas. Esbozo de una teoría general (Buenos Aires: Cangallo, 1978 ), 43. 
que constan en el texto constitucional. En las nuevas constituciones latinoamericanas se han hecho constar fines específicos vinculados directamente a la actividad financiera del Estado, ya que, si bien el fin último contenido en todo texto fundamental es la consecución efectiva de los derechos contenidos en tales textos, los constituyentes colombianos, venezolanos, ecuatorianos y bolivianos han hecho hincapié en ciertas necesidades puntuales.

El artículo 366 de la Constitución colombiana declara como finalidades sociales del Estado: el bienestar general y el mejoramiento de la calidad de vida de la población, y enuncia como objetivo fundamental de su actividad la solución de las necesidades insatisfechas de salud, de educación, de saneamiento ambiental y de agua potable. El artículo 299 del texto venezolano, por su parte, enuncia como fines del Estado el de asegurar el desarrollo humano integral y una existencia digna y provechosa para la colectividad, debiéndose generar fuentes de trabajo, alto valor agregado nacional, elevar el nivel de vida de la población y fortalecer la soberanía económica del país, garantizando la seguridad jurídica, solidez, dinamismo, sustentabilidad, permanencia y equidad del crecimiento de la economía, para lograr una justa distribución de la riqueza mediante una planificación estratégica, democrática, participativa y de consulta abierta. En Ecuador, el artículo 285 del texto constitucional señala como objetivos específicos de la política fiscal: el financiamiento de servicios, inversión y bienes públicos; la redistribución del ingreso por medio de transferencias, tributos y subsidios adecuados; y, la generación de incentivos para la inversión en los diferentes sectores de la economía y para la producción de bienes y servicios, socialmente deseables y ambientalmente aceptables. Y en Bolivia, finalmente, el artículo 32.II. de la Constitución, manifiesta que las asignaciones que se realicen atenderán especialmente a la educación, la salud, la alimentación, la vivienda y el desarrollo productivo.

Pero, la ejecución de tales fines demanda "una acción eminente y necesariamente política", ${ }^{50}$ ya que de aquella se desprende el detalle de necesidades públicas cuya satisfacción se pretende, las cuales - de manera cuestionable- son enlistadas bajo la influencia inevitable de ideologías y decisiones políticas de gobierno, ${ }^{51}$ es decir, de ciertos grupos hegemónicos de momento. ${ }^{52}$ Por lo que, a fin de entrever la dinamia

50. Benvenuto Griziotti, Principios de ciencia de las finanzas (Buenos Aires: Depalma, 1959), 15.

51. Vid. Dino Jarach, Finanzas públicas y Derecho tributario, 3a. ed. (Buenos Aires: Abeledo-Perrot, 2003), 44; vid. Jarach, Finanzas públicas. Esbozo de una teoría general, 19.

52. La teoría de la elección pública es la rama de la economía que estudia la manera en que toman sus decisiones los poderes políticos. La elección pública es el proceso por el que se transforman las preferencias individuales en decisiones colectivas, a través de un sistema político que permite tomar-se espera racionalmente- tales decisiones. En los países democráticos el proceso de elección pública generalmente pende de los sistemas de votación, los cuales se legitiman bajo las reglas de unanimidad o de mayoría. Bajo la regla de unanimidad (o consenso), es mucho más difícil mejorar el bienestar de los individuos porque todos deben estar de acuerdo para la toma 
legítima de la actividad financiera del Estado conviene analizarla en su conjunto; esto es, en aquellos elementos que en ella siempre concurren: la obtención de ingresos públicos, la determinación y elección de las necesidades que se busca satisfacer y la aprobación del gasto público. Sin embargo, dada la limitada extensión del presente ensayo, en esta oportunidad se analizará parcialmente solo el primero de sus componentes: la noción elemental contemporánea de los ingresos fiscales, en particular, de los provenientes de la gestión del patrimonio público.

No obstante, antes de continuar con lo señalado, cabe advertir que, si bien el Estado para la realización de sus fines debe llevar a cabo las funciones necesarias en lo referente a la selección de necesidades y objetivos como en lo relativo a la obtención de los medios, sean tales pecuniarios o de otro tipo, y a la gestión de aquellos, la actividad financiera en la actualidad (en las nuevas constituciones andinas) no tiene como única finalidad la obtención de ingresos suficientes para cubrir el gasto público, sino que pretende, además, impulsar la economía dirigiéndola y regulándola, ${ }^{53}$ supuesto en el que las relaciones entre la política, el derecho y la economía se entrelazan de tal manera que resulta muy difícil disociarlas. ${ }^{54}$ Por lo que, en el desarrollo de la noción elemental anunciada se buscará un enfoque interdisciplinario que permita de mejor manera percibir los pilares y vínculos de tales dimensiones, que se materializan finalmente en los textos constitucionales de cada uno de los Estados.

\section{LOS INGRESOS FISCALES}

Con cierta generalidad e imprecisión, se han utilizado indistintamente los vocablos recursos e ingresos para referirse a los valores dinerarios que obtiene el Estado para el sostenimiento del gasto público; sin embargo, no son lo mismo.

Si bien recurso, semánticamente, caracteriza al medio de cualquier clase que sirve para conseguir lo que se pretende en caso de necesidad, ${ }^{55}$ este no trata únicamente

de cualquier decisión, en tanto bajo la regla de la mayoría, el grupo mayoritario puede tomar decisiones y votar a favor de cualquier propuesta que mejore su renta, pero, tales decisiones pueden ser eficientes y justas como ineficientes e injustas. Por ello, Kenneth Arrow (el Teorema de Arrow) demostró que no existe ningún sistema de votación, basado en el criterio de la mayoría, que garantice la eficiencia, respete las preferencias individuales y no dependa del orden del día, de modo que no existe sistema alguno que garantice que la votación por mayoría sea coherente y que llevará a la sociedad a su posición más deseable. Cfr. Samuelson y Nordhaus, Economía, 367-76; cfr. Cristián Larroulet y Francisco Mochón, Economía (Madrid: McGraw-Hill, 1996), 87-91.

53. Cfr. María de la Luz Mijangos Borja, "Conceptos generales del derecho financiero", en Beatriz Dolores Bonifaz Chapoy, dir., Panorama del derecho mexicano. Derecho financiero (México: UNAM, s. f.), 3-4.

54. Vid. Gabriel Santiago Galán Melo, La igualdad juridica y la no discriminación en el régimen tributario (Quito: Corporación de Estudios y Publicaciones, 2013), 96-103.

55. Cfr. Juan Palomar de Miguel, Diccionario para juristas (México: Porrúa, 2012), 1332-4. 
del caudal -en dinero- que ingresa a la cuenta del tesoro nacional y que constituye el ingreso fiscal. El recurso hace relación al procedimiento (la fuente) mediante el cual el Estado obtiene el poder de compra necesario para efectuar las erogaciones propias de su actividad financiera, ${ }^{56}$ en tanto que el ingreso engloba los montos específicos que en dinero (moneda con valor de cambio) recibe el Estado para sostener los gastos que debe realizar a efecto de cumplir con sus finalidades. Villegas no es muy claro en la distinción entre ambas expresiones; si bien denota una diferencia entre aquellas, finalmente, las caracteriza uniformemente como valores que se devengan a favor del Estado para cumplir sus fines, y que con dicho carácter ingresan en la tesorería pública, aunque deja entrever discretamente que los recursos se configuran ut causa de los ingresos fiscales que efectivamente integran la cuenta del tesoro nacional. ${ }^{57}$

Jarach, por el contrario, es explícito en cuanto a la distinción que plantea. Para aquel, si bien ambas nociones se encuentran íntimamente relacionadas, los recursos públicos hacen relación a los procedimientos que, constitucional y legalmente, el Estado puede realizar para la consecución y obtención de los ingresos fiscales, ya que estos últimos no son sino los caudales específicos que ingresan finalmente a la tesorería del Estado y que son el resultado del ejercicio de los primeros. ${ }^{58}$ Falcón y Tella, asimismo, considera los recursos públicos como "aquellos institutos jurídicos cuya finalidad, principal o subsidiaria, es proporcionar ingresos al ente público"; 59 de modo que los ingresos fiscales no son sino la consecuencia directa del ejercicio del poder público sobre los recursos del Estado. Por ello, puede notarse -inter alia-en cualquier Estado contemporáneo, en la configuración de su estructura financiera, la presencia de recursos patrimoniales, recursos tributarios y recursos de crédito o endeudamiento, que a su vez son generadores, en orden, de los ingresos por la gestión del patrimonio público, de los ingresos tributarios y de los ingresos por el endeudamiento público.

Sainz de Bujanda, por su parte, esboza una estructura de hacienda pública algo más compleja a la sola distinción entre los recursos públicos y los ingresos fiscales, la que, en todo caso, da cuenta de su innegable diferencia. Para aquel, la hacienda pública está compuesta por tres elementos de contenido financiero: 1. los recursos de la hacienda pública conformados por los tributos, monopolios, deuda pública y patrimonio del Estado; 2. los derechos económicos de la hacienda pública conformados por los créditos tributarios, derechos de participación en la renta de monopolios, derechos derivados de la emisión de empréstitos, y derechos sobre los bienes patrimoniales y sobre sus productos; y 3 . los ingresos públicos conformados de prestaciones

56. Cfr. Jarach, Finanzas públicas. Esbozo de una teoría general, 221.

57. Cfr. Villegas, Manual de finanzas públicas, 155-6.

58. Cfr. Jarach, Finanzas públicas. Esbozo de una teoría general, 221-2.

59. Ramón Falcón y Tella, Derecho financiero y tributario, 2a. ed. (Madrid: Universidad Complutense, 2013), 17. 
tributarias, ingresos monopolísticos, productos de la deuda pública y rendimientos patrimoniales,${ }^{60}$ haciendo notar una estructura financiera multinivel e interdependiente entre los recursos públicos, los derechos de contenido económico del Estado y los ingresos fiscales, todos distintos entre sí pero vinculados ordenadamente como fuente-instrumento-resultado.

En Ecuador, la definición de recursos públicos está en el artículo 3 de la Ley Orgánica de la Contraloría General del Estado, en concordancia con el artículo 76 del Código Orgánico de Planificación y Finanzas Públicas, que establece que, para efecto de dicha ley, se entenderán por recursos públicos todos los bienes, fondos, títulos, acciones, participaciones, activos, rentas, utilidades, excedentes, subvenciones y todos los derechos que pertenecen al Estado y a sus instituciones, sea cual fuere la fuente de la que procedan, inclusive los provenientes de préstamos, donaciones y entregas que, a cualquier otro título, realicen a favor del Estado o de sus instituciones, personas naturales o jurídicas u organismos nacionales o internacionales; y que los recursos públicos no pierden su calidad de tales al ser administrados por corporaciones, fundaciones, sociedades civiles, compañías mercantiles y otras entidades de derecho privado, cualquiera hubiere sido o fuere su origen, creación o constitución, hasta tanto los títulos, acciones, participaciones o derechos que representen ese patrimonio, sean transferidos a personas naturales o personas jurídicas de derecho privado, de conformidad con la ley; realizándose la precisión -con claridad- de que, los anticipos correspondientes a la contratación pública no pierden su calidad de recurso público hasta el momento de ser devengados.

En cambio, la definición de ingresos fiscales se obtiene de la lectura del artículo 78 del Código Orgánico de Planificación y Finanzas Públicas, el cual tiene por objeto en verdad clasificar los ingresos en permanentes y no permanentes, pero refiere elementos que permite abstraer una definición unívoca: son ingresos fiscales los ingresos de recursos públicos que el estado a través de sus instituciones y organismos públicos reciben. En cuyo caso, en Ecuador, legalmente se distinguen los recursos públicos de los ingresos fiscales por cuanto los primeros son fuente y generación de los segundos.

Ahora bien, atendiendo únicamente a los ingresos fiscales -y valiéndonos del planteamiento regular hecho por Sainz de Bujanda y la discriminación que realiza Giuliani Fonrouge-, estos se distinguen en: 1. ingresos producidos por los bienes del dominio público estatal o por las empresas y servicios públicos, 2. tributos y sanciones fiscales, y 3. crédito público. ${ }^{61}$ Los primeros consecuencia de la gestión del patrimonio del es-

60. Cfr. Fernando Sainz de Bujanda, Sistema de derecho financiero, vol. 1 (Madrid: Facultad de la Universidad Complutense, 1985), 32-3.

61. Vid. Giuliani Fonrouge, Derecho financiero, 197. 
tado y de su actividad como operador económico, en tanto que los segundos y terceros como consecuencia del ejercicio de las potestades de imperium del mismo Estado: los tributos como resultado del ejercicio de su potestad tributaria, las sanciones fiscales como resultado de su potestad de control y sanción, y el producto del crédito público como resultado de su potestad para el endeudamiento.

Y a fin de cumplir con el objetivo del presente ensayo, y especificar al primero de estos ingresos que percibe el Estado, ${ }^{62}$ a continuación se realizará una sucinta revisión de esta noción particular dentro de los textos de las nuevas constituciones andinas, determinando la fuente de tales ingresos fiscales y su proyección en la actividad financiera del Estado.

\section{INGRESOS PRODUCTO DE LA GESTIÓN DEL PATRIMONIO PÚBLICO}

Los ingresos fiscales producto de la gestión del patrimonio público se generan precisamente en la explotación que realiza el Estado de los bienes de dominio público. El dominio en su acepción tradicional supone, con mérito al vínculo jurídico de poder directo entre el sujeto y el objeto del derecho, el ejercicio de tres facultades: el uso, el goce y la disposición de la cosa, ${ }^{63} \sin$ embargo, en lo que conviene al ámbito del dominio público, la facultad de disposición se encuentra ausente, pues, tratándose de los bienes que naturalmente pertenecen a dicho reducto, son características comunes a ellos: la inalienabilidad, la imprescriptibilidad y la inembargabilidad; ${ }^{64}$ es decir, la total indisponibilidad de aquel cúmulo de bienes que conforman el patrimonio del

62. La clasificación de los ingresos fiscales señalada obedece a la fuente u origen en la que se genera cada uno de ellos; empero, no se trata de la única clasificación que se haya realizado a los ingresos fiscales, pero parece es la más útil para comprender las nociones fundamentales del derecho constitucional-presupuestario. Vid. Villegas, Manual de finanzas públicas, 159-65; vid. Falcón y Tella, Derecho financiero y tributario, 20-1. Cabe anotar, además, que las categorías que surgen a raíz de los criterios de clasificación de los ingresos fiscales conviene a la realidad plasmada en los diferentes textos constitucionales de cada Estado; así, por ejemplo, en Estados Unidos de América, en el que constitucionalmente no existe una noción manifiesta de bienes de dominio público por afectación, los ingresos fiscales por su origen se clasifican en impuestos, tasas y empréstitos. Vid. Richard A. Musgrave y Peggy B. Musgrave, Hacienda pública. Teórica y aplicada, Juan Francisco Corona Ramón, Juan Carlos Costas Terrones y Amelia Díaz Álvarez, trad., 5a. ed. (Madrid: McGraw-Hill, s. f.), 255. Valdés Costa hace un detalle profundo, y bastante completo, enunciando varios criterios de clasificación de los ingresos fiscales. Vid. Ramón Valdés Costa, Curso de derecho tributario, 2a. ed. (Bogotá, Depalma-Temis-Marcial Pons, 1996), 1-21.

63. Vid. Luis Guillermo Velásquez Jaramillo, Bienes, 11a. ed. (Medellín, Librería Jurídica Comlibros, 2008), 207-8 y 221-2; Arturo Alessandri Rodríguez y Manuel Somarriva Undurraga, Curso de derecho civil. Los bienes y los derechos reales, 3a. ed. (Santiago: Editorial Nascimento, s. f.), 136 y 164-78; Genaro Eguiguren, Derecho de propiedad en el Ecuador (Quito, Corporación Editora Nacional, 2008), 55-6 y 61-4.

64. Vid. Velásquez Jaramillo, Bienes, 63-75. 
estado. ${ }^{65} \mathrm{La}$ facultad de disposición, configurativa del dominio, no es sino la prerrogativa que tiene el sujeto para desprenderse libremente del derecho a la propiedad sobre la cosa, ${ }^{66}$ sea que lo haga por renuncia, abandono o enajenación. ${ }^{67}$ Pero el Estado no puede renunciar, abandonar ni enajenar el patrimonio que constitucionalmente se le ha reconocido, el cual forma parte integrante de su territorio y en consecuencia no puede ser dispuesto. ${ }^{68}$

Por ejemplo, en Colombia, los artículos 63, 72 y 75 de la constitución declaran a los bienes de uso público, parques naturales, tierras comunales de grupos étnicos, tierras de resguardo, al patrimonio arqueológico y cultural colombiano, al espectro electromagnético y demás que determine la ley, inalienables, imprescriptibles e inembargables. La constitución venezolana por su parte, en el artículo 12, declara a los yacimientos mineros y de hidrocarburos, cualquiera que sea su naturaleza, existentes en el territorio venezolano, bajo el lecho del mar territorial, en la zona económica exclusiva y en la plataforma continental, y a las costas marinas, bienes del dominio público y por tanto inalienables e imprescriptibles. Ecuador asimismo declara, en los artículos 1, 12, 317, 318 y 408, inalienables, irrenunciables e imprescriptibles los recursos no renovables que pertenecen a su patrimonio, en particular, el agua a la cual se la considera uno de los recursos estratégicos del Estado, y en general, los productos del subsuelo, yacimientos minerales y de hidrocarburos, substancias cuya naturaleza sea distinta de la del suelo, incluso los que se encuentren en las áreas cubiertas por las aguas del mar territorial y las zonas marítimas; así como la biodiversidad y su patrimonio genético y el espectro radioeléctrico. En Bolivia, el artículo 349.I. señala que los recursos naturales son de propiedad y dominio directo, indivisible e imprescriptible del pueblo boliviano, y que corresponde al Estado su administración en función del interés colectivo; en cuyo caso, en el texto se ha omitido caracterizar al patrimonio público con las restricciones de la inalienabilidad e inembargabilidad, que parece consecuencia práctica inevitable del reconocimiento de la titularidad directa del pueblo boliviano; sin embargo, en el artículo 99.I. sí consta la caracterización plena tratándose solamente del patrimonio cultural del pueblo boliviano.

65. Cfr. Gabriel S. Galán Melo, "Ecuador: prolegómeno a la constitución económica, el derecho a la propiedad en todas sus formas en la Constitución de 2008”, en Claudia Storini y Rafael Lara González, edit., Constitución económica en Latinoamérica (Quito: Corporación de Estudios y Publicaciones, 2016), 120-1.

66. Cfr. Velásquez Jaramillo, Bienes, 221; cfr. Rodríguez y Somarriva Undurraga, Curso de derecho civil. Los bienes y los derechos reales, 170; cfr. Eguiguren, Derecho de propiedad en el Ecuador, 63-4.

67. Vid. Rodríguez y Somarriva Undurraga, Curso de derecho civil. Los bienes y los derechos reales, 170-8.

68. Contrario sensu, Martín Queralt, Lozano Serrano, Tejerizo López y Casado Ollero sostienen que los ingresos patrimoniales provienen de la explotación y enajenación de los bienes que constituyen el patrimonio de los entes públicos, los cuales se afirma son distintos de los bienes de dominio o uso público, y que por ello, se rigen por normas del derecho privado. Cfr. Juan Martín Queralt, Carmelo Lozano Serrano, José Manuel Tejerizo López y Gabriel Casado Ollero, Curso de Derecho financiero y tributario, 17a. ed. (Madrid: Tecnos, 2006), 48. 
Por ello, la noción clásica del derecho a la propiedad respecto de los bienes del estado es inaplicable: resulta imposible sostener que el dominio público es una especialidad del dominio común; de ahí la necesidad de desarrollar un enfoque que le pertenezca adecuadamente al demanio ${ }^{69}$ y que deje de explicarlo inútilmente como una simple singularidad del derecho privado de la propiedad. ${ }^{70}$ Por ejemplo, la acepción tradicional privada de la propiedad se limita intrínsecamente en su ejercicio por la función social: por el interés público y el respeto al derecho ajeno, ${ }^{71}$ en tanto que en el ámbito del dominio público (o demanio), aquella función -que sirve de limitación en la configuración del derecho privado- es el contenido mismo de su ejercicio, ${ }^{72} \mathrm{de}$ modo que los poderes de la administración pública con relación a los bienes que le pertenecen al Estado encuentran su origen y fundamento en la afectación del objeto ${ }^{73}$ y no en el relacionamiento directo entre el sujeto y la cosa como ocurre en el dominio privado; es decir, tales bienes se legitiman por el destino específico que deben cumplir, los cuales si bien no pueden ser dispuestos, pueden ser administrados, controlados y gestionados -con fines fiscales- en los términos establecidos por la ley. ${ }^{74}$

En Ecuador, el artículo 66, número 26, de la Constitución de la República, al referirse al sistema de protección del derecho a la propiedad enuncia a más de la función social, una función de responsabilidad ambiental, que se adecua obviamente con la clara inclinación que el texto constitucional tiene hacia la protección de la naturaleza, pero que, deberá irse desarrollando paulatinamente con la actividad legislativa, ya que no existe aún claridad sobre el contenido y alcance de dicha función que le permita asentarse autónomamente y particularizarse de la función social.

69. Morillo-Velarde Pérez utiliza la denominación demanio para referirse -como institución jurídica autónoma- al dominio público, del cual si bien reconoce su pertenencia al derecho patrimonial lo distingue de la propiedad privada y de los patrimonios públicos: "propiedad privada, patrimonios públicos y dominio público son tres conceptos sustantivos del Derecho patrimonial que, de esta manera, pierde su tradicional adscripción preferente al Derecho privado y se afirma como un terreno claramente interdisciplinar en el que, una vez más, se difuminan los contornos entre el Derecho público y el privado. En realidad, son los instrumentos normativos básicos a través de los cuales el poder del Estado - titular originario de todos los bienes "articula el régimen de las cosas en nuestro derecho". Cfr. José Ignacio Morillo-Velarde Pérez, Dominio Público (Madrid: Trivium, s. f.), 34.

70. Cfr. Morillo-Velarde Pérez, Dominio Público, 12-5; vid. Cosculluela Montaner, Manual de Derecho administrativo Parte general, 646-7.

71. Cfr. Eguiguren, Derecho de propiedad en el Ecuador, 65.

72. Morillo-Velarde al respecto manifiesta: “[...] porque la invocación de la propiedad para definir la naturaleza jurídica del dominio público le proporcionaba un engarce suficiente titular-cosa, dado que lo que realmente determinante para ella era el concepto de afectación en el que ha encontrado la base necesaria para explicar lo que realmente le interesaba: las prerrogativas, los privilegios y las exorbitancias característicos del régimen demanial, y esto no se puede negar”. Cfr. Morillo-Velarde Pérez, Dominio Público, 34.

73. Ibíd., 23.

74. Cfr. Galán Melo, "Ecuador: prolegómeno a la constitución económica...", 121-2. 
Morillo-Velarde Pérez señala que "propiedad y demanio son instituciones yuxtapuestas, cada una de ellas, con una finalidad específica y unos perfiles propios en el ámbito del Derecho patrimonial". ${ }^{75} \mathrm{Al}$ demanio le interesa, en particular, el conjunto de prerrogativas, privilegios y exorbitancias sobre el patrimonio indisponible del Estado. ${ }^{76} \mathrm{Y}$ es a través del ejercicio, precisamente, de tales prerrogativas, privilegios y exorbitancias contenidas en la ley ${ }^{77}$ que el Estado obtiene racionalmente ingresos por la gestión de su patrimonio, como por ejemplo: el dinero que obtiene por la explotación y venta (directa o en coparticipación) del petróleo, de ciertos minerales -como los diamantes-, o de determinados metales -como el oro o el cobre-, que se obtienen del cúmulo de bienes públicos no-disponibles. Ahora bien, los bienes enunciados parecerían resultado obvio del sistema constitucional de reconocimiento y protección territorial del estado, ${ }^{78}$ sin embargo, no son los únicos que se encuentran bajo el $d e-$ manio del mismo. Pertenecen al ámbito demanial también grandes infraestructuras destinadas al uso público como carreteras o puentes, u otras afectadas a la prestación de servicios públicos como puertos, hospitales o escuelas.

$\mathrm{Al}$ respecto, Cosculluela Montaner indica que existen, por un lado, bienes de dominio público por naturaleza que son los declarados como tales por la constitución y la ley, y reúnen las características físicas propias de su denominación como las aguas, playas, etc.; y, por otro, bienes de dominio público por afectación, que son fruto de la obra humana y que comprenden a su vez a los bienes afectos al uso público y a los bienes afectos al servicio público. Entre los primeros menciona las carreteras, caminos, vías pecuarias, puentes, calles, parques; y, entre los segundos, las obras de defensa militar, vías férreas, aeropuertos, puertos, hospitales, mataderos, mercados, museos, escuelas, universidades públicas, bibliotecas, cementerios, piscinas y campos de deporte ${ }^{79}$ los primeros destinados al uso libre y gratuito (en principio al menos) de la población, y los segundos que sirven de soporte físico a la explotación de un servicio público, con o sin costo. De la administración, regulación, control y gestión de parte de los bienes de dominio público por naturaleza -de aquellos calificados como estratégicos- el Estado obtiene inevitablemente ingresos fiscales, pero también lo hace por la prestación de algunos servicios públicos.

75. Morillo-Velarde Pérez, Dominio Público, 33.

76. Ibíd., 34 y 130-52.

77. Cosculluela Montaner hace hincapié en la necesidad del establecimiento (constitucional) de la reserva de ley para la declaración del carácter demanial de un bien en particular. Vid. Cosculluela Montaner, Manual de Derecho administrativo. Parte general, 647.

78. Por ejemplo el artículo 102 de la constitución colombiana señala textualmente: "El territorio, con los bienes públicos que de él forman parte, pertenecen a la Nación".

79. Cfr. Cosculluela Montaner, Manual de Derecho administrativo. Parte general, 647-8. 
En Venezuela, por ejemplo, según lo indica el artículo 302 de la Constitución, el Estado se reserva, por razones de conveniencia nacional, la actividad petrolera y otras industrias, explotaciones, servicios y bienes de interés público y de carácter estratégico calificados como tal por una ley orgánica; asimismo, el artículo 303 del mismo texto constitucional señala que por razones de soberanía económica, política y estrategia nacional, el Estado debe conservar la totalidad de las acciones de Petróleos de Venezuela S.A. o del ente creado para el manejo de la industria petrolera. En Ecuador, por su parte, por disposición del artículo 313 de la Constitución, el Estado se ha reservado el derecho de administrar, regular, controlar y gestionar aquellos sectores que por su trascendencia y magnitud tienen decisiva influencia económica, social, política o ambiental, a los cuales califica de estratégicos, señalando como tales: la energía en todas sus formas, las telecomunicaciones, los recursos naturales no renovables, el transporte y la refinación de hidrocarburos, la biodiversidad y el patrimonio genético, el espectro radioeléctrico, el agua, y otros que determine la ley. Inclusive, la Corte Constitucional ecuatoriana, mediante Sentencia (interpretativa) No. 001-12-SIC-CC, publicada en el Suplemento del Registro Oficial No. 629 de 30 de enero de 2012, ha dicho que las empresas públicas únicamente gozan de la facultad de gestionar los sectores estratégicos para los que hubieren sido autorizadas, sin que les esté permitido delegar a la iniciativa privada la gestión de tales sectores, ya que solo el Estado central puede autorizar a las empresas públicas la gestión de los sectores estratégicos; pero que, en todo caso, a través de las autoridades de control y regulación competentes del gobierno central, podrá delegarse a empresas mixtas, o excepcionalmente a la iniciativa privada o economía popular y solidaria, la gestión de sectores estratégicos, en los casos contemplados en la ley de la materia o sector pertinente.

En Bolivia, asimismo, el artículo 348 del texto constitucional otorga el carácter de estratégico a los recursos naturales, siendo tales los minerales en todos sus estados, los hidrocarburos, el agua, el aire, el suelo y el subsuelo, los bosques, la biodiversidad, el espectro electromagnético y todos aquellos elementos y fuerzas físicas susceptibles de aprovechamiento, cuya dirección, control y regulación corresponde con exclusividad al estado, quien además se reserva el derecho de desarrollar tales sectores estratégicos para el crecimiento económico y social del país con equidad, y ejercita su derecho participando como inversionista, a través de la inversión estatal productiva, en el marco de lo establecido en la ley, aunque inversionistas privados podrían desarrollar actividades económicas en sectores estratégicos, con sujeción a los derechos que el Estado otorgue para el efecto en el marco de las normas y políticas de desarrollo económico y social del país, como lo ordena el artículo 6 de la Ley No. 516, de 4 de abril de 2014, denominada: Ley de Promoción de Inversiones.

Ahora bien, servicio público es la actividad por la cual la administración pública ejecuta, de manera regular y continua, la prestación de una utilidad singular a los ciu- 
dadanos, que satisface además una necesidad general que se considera esencial para el funcionamiento de la sociedad..$^{80}$ Por ello - porque satisface necesidades de orden público-, es el Estado quien directamente o mediante concesión, asociación o cualquier otra modalidad contractual, presta el servicio público con notoria exclusividad, pues, el estado es el que garantiza su prestación y finalmente lo regula y controla. Duguit señala que el servicio público es toda actividad cuyo cumplimiento debe ser asegurado, regulado y controlado por el poder público, porque es indispensable para la realización y desarrollo de la interdependencia social ${ }^{81}$ por lo que el Estado debe asumir la ejecución monopólica de determinadas actividades económicas: las calificadas de servicio público por la constitución o la ley. El ejercicio de tales actividades económicas, que supone inevitablemente la administración, regulación, control y gestión de los bienes afectos a tales servicios, generan asimismo ingresos para el Estado, como podría ocurrir con las centrales hidroeléctricas respecto del servicio de alumbrado; debiendo asimilar en tal caso, que el ingreso fiscal del estado constituye en realidad la diferencia de la relación entre el valor percibido por la prestación del servicio público y el gasto destinado a dicha prestación. ${ }^{82}$

De ahí que los ingresos producto de la gestión del patrimonio público sean, o bien ingresos patrimoniales en sentido estricto: los producidos por la administración, regulación, control y gestión de los bienes naturales y estratégicos del demanio (o dominio público), o bien ingresos monopolísticos ${ }^{83}$ provenientes de la administración, regulación, control y gestión de los bienes afectos a la prestación de determinados servicios públicos; debiendo advertirse, con cierta obviedad, que la gestión de los sectores estratégicos del Estado inevitablemente es también monopólica, pero tal connotación no está en capacidad de caracterizar a los ingresos patrimoniales en sentido estricto, por cuanto no existe una proyección económica real que afecte la participación de terceros en la ejecución de tales actividades ya que inevitablemente se trata de un reducto ex-

80. Cfr. Cosculluela Montaner, Manual de Derecho administrativo. Parte general, 611.

81. Vid. León Duguit, Manual de derecho constitucional (Granada: Comares, 2005), 65.

82. En Ecuador, el artículo 91 del Código Orgánico de Planificación y Finanzas Públicas señala que: "Los recursos provenientes de actividades empresariales públicas nacionales ingresarán al Presupuesto General del Estado una vez descontados los costos inherentes a cada actividad y las inversiones y reinversiones necesarias para el cumplimiento de la finalidad de cada empresa".

83. Martín Queralt, Lozano Serrano, Tejerizo López y Casado Ollero sostienen que en ocasiones el Estado decide que un determinado servicio sea prestado, de forma exclusiva, por él, o que la adquisición, producción y venta de determinados productos solo pueda realizarla asimismo el Estado; en cuyo caso, se configuraría un monopolio de derecho, es decir, aquel que se encuentra tutelado por el mismo ordenamiento jurídico. Tal configuración solo es posible por la legitimidad de sus fines, ya que el estado establecería monopolios o bien para mejorar la prestación de un determinado servicio público o bien para obtener ingresos; pero que, inclusive en aquellos que persiguen fines no fiscales, el fin recaudatorio es de notable interés. Vid. Queralt, Lozano Serrano, Tejerizo López y Casado Ollero, Curso de Derecho financiero y tributario, 53-5. 
clusivo y puramente estatal, en tanto que, tratándose de los ingresos monopolísticos, no es sino el mismo Estado el que condiciona y restringe la participación de ciertos operadores económicos - distintos de aquel- en la prestación de un servicio en particular, que ha sido mayoritariamente reconocido como público o de interés general.

Ahora bien, para finalizar cabe indicar que la noción de los ingresos producto de la gestión del patrimonio público no genera inconveniente craso respecto de su acepción o contenido, pero sí de los límites y exorbitancias que posee el Estado para obtenerlos; es decir, la mayor dificultad actual se encuentra en establecer las delimitaciones en el ejercicio del poder político en la administración, regulación, control y gestión del patrimonio público sin que se consuma en el proceso, de manera arbitraria, los recursos naturales de la nación, y sin que afecte los derechos de determinados colectivos que se encuentran natural y especialmente vinculados con el entorno de tales recursos, pero sin menoscabar - a su vez- de modo alguno, sus fines esencialmente recaudatorios (fiscales), y dejando de lado la deslealtad económica en la configuración de sus monopolios fiscales. Debe insinuarse también la problemática respecto de los ingresos que el estado podría producir como un operador económico más en el mercado y de su legitimidad, pero aquella no es objeto del presente estudio.

\section{CONCLUSIONES}

a) El Estado, más allá de su tipología, fue constituido jurídica e institucionalmente para que cumpla determinadas finalidades que satisfagan las necesidades comunes del colectivo gobernado. En un Estado constitucional tales finalidades son amplias y constan necesariamente en el texto de la Constitución. Para que el Estado pueda realizar sus fines necesita ineludiblemente los medios idóneos para lograrlo, entre ellos, recursos económicos suficientes, encaminados al sostenimiento del gasto público. Para ello, ejecuta una serie continuada de actos y actividades determinadas que le permite recaudarlos. Tales recursos económicos se obtienen a través de ingresos tributarios y no tributarios, los primeros, provenientes del ejercicio de la potestad pública de imponer tributos a los habitantes de un Estado en particular y los segundos, vinculados a la capacidad de aquel para obtener ingresos por la adecuada gestión de su patrimonio o para obtener lícitamente cualquier otra fuente de financiamiento, inclusive, a través del endeudamiento público. De esto trata la actividad financiera del Estado: de la función que este desarrolla para procurarse los recursos económicos indispensables para financiar el gasto público.

b) Los ingresos fiscales son la consecuencia directa del ejercicio del poder público sobre los recursos del Estado. Todo Estado contemporáneo, en la configuración de su estructura financiera en el texto constitucional, prevé la existencia de 
recursos patrimoniales, recursos tributarios y recursos de crédito o endeudamiento, que a su vez sirven de fuente y son generadores, en su orden, de los ingresos por la gestión del patrimonio público, de los ingresos tributarios y de los ingresos por el endeudamiento público. Los recursos públicos del Estado como fuente generadora de los ingresos fiscales se atan a los procedimientos mediante los cuales obtiene el poder de compra indispensable para efectuar los gastos propios de su actividad financiera, en tanto que los ingresos fiscales sencillamente engloban los montos específicos que en moneda con valor de cambio recibe el Estado, en su cuenta única, para sostener las erogaciones que debe realizar a efecto de cumplir con sus finalidades.

c) Los ingresos fiscales producto de la gestión del patrimonio público -en Colombia, Venezuela, Ecuador y Bolivia- se generan en la explotación que realiza el Estado de los bienes estratégicos del demanio público y de los bienes afectos a la prestación de determinados servicios públicos. Al demanio público le interesa el conjunto de prerrogativas, privilegios y exorbitancias sobre el patrimonio indisponible del Estado, es decir, sobre aquel conjunto de bienes del cual el Estado no es en realidad propietario -desde la construcción tradicional del dominum - sino un gestor responsable. Los ingresos producto de la gestión del patrimonio público pueden ser ingresos patrimoniales en sentido estricto, es decir, los producidos por la administración, regulación, control y gestión de los bienes naturales y estratégicos del demanio público, o, ingresos monopolísticos, provenientes de la administración, regulación, control y gestión de los bienes afectos a la prestación de determinados servicios públicos, reconocidos como tales por la constitución o la ley.

\section{BIBLIOGRAFÍA}

Abramovich, Víctor, y Christian Courtis. "Hacia la exigibilidad de los derechos económicos, sociales y culturales. Estándares internacionales y criterios de aplicación ante los tribunales locales". En Martín Abregú y Christian Courtis, edit., La aplicación de los tratados internacionales sobre derechos humanos por los tribunales locales. Buenos Aires: Ed. Del Puerto/CELS, 1997.

Ahumada, Guillermo. Tratado de finanzas públicas, tomo 1, 4a. ed. Buenos Aires: Plus Ultra, 1969.

Alessandri Rodríguez, Arturo, y Manuel Somarriva Undurraga. Curso de derecho civil. Los bienes y los derechos reales, 3a. ed. Santiago: Editorial Nascimento, s. f.

Bodin, Jean. Los seis libros de la República, Pedro Bravo Gala, trad. Madrid: Tecnos, 1997.

Brewer-Carías, Allan R. "Reflexiones sobre la constitución económica". En Sebastián MartínRetortillo, coord., Estudios sobre la Constitución Española. Homenaje al Profesor Eduardo García de Enterría, tomo V. Madrid: Civitas, 1991. 
Cosculluela Montaner, Luis. Manual de Derecho administrativo. Parte general, 21a. ed. Pamplona: Civitas/Thomson Reuters/Arazandi, 2010.

De Lojendio, Ignacio María. "Derecho Constitucional Económico”. En Luis Sánchez Agesta, coord., Constitución y Economía. La Ordenación del Sistema Económico en las Constituciones Occidentales. Madrid: Editorial Revista de Derecho Privado/Editoriales de Derecho Reunidas, 1977.

Duguit, León. Manual de derecho constitucional. Granada: Comares, 2005.

Eguiguren, Genaro. Derecho de propiedad en el Ecuador. Quito: Corporación Editora Nacional, 2008.

Falcón y Tella, Ramón. Derecho financiero y tributario, 2a. ed. Madrid: Universidad Complutense, 2013.

Ferrajoli, Luigi. "Estado Social y Estado de Derecho". En Víctor Abramovich, María José Añón y Christián Courtis, comp., Derechos sociales. Instrucciones de uso. México: DJC, 2003.

Ferreiro Lapatza, Juan José. Curso de Derecho financiero español. Instituciones, 25a. ed. Madrid: Marcial Pons, 2006.

Fraga, Gabino. Derecho Administrativo. México: Porrúa, 1990.

Galán Melo, Gabriel Santiago. “Ecuador: prolegómeno a la constitución económica, el derecho a la propiedad en todas sus formas en la Constitución de 2008". En Claudia Storini y Rafael Lara González, edit., Constitución económica en Latinoamérica. Quito: Corporación de Estudios y Publicaciones, 2016.

---. La igualdad jurídica y la no discriminación en el régimen tributario. Quito: Corporación de Estudios y Publicaciones, 2013.

Giuliani Fonrouge, Carlos María. Derecho financiero, tomo 1, 9a. ed. Buenos Aires: La Ley, 2004.

Griziotti, Benvenuto. Principios de ciencia de las finanzas. Buenos Aires: Depalma, 1959.

Heller, Hermann. Teoría del Estado. México: Fondo de Cultura Económica, 1992.

Hobbes, Thomas. Leviatán o La materia, forma y poder de una República Eclesiástica y Civil. Bogotá: Skala, 1982.

Jarach, Dino. Finanzas públicas. Esbozo de una teoría general. Buenos Aires: Cangallo, 1978.

---. Finanzas públicas y derecho tributario, 3a. ed. Buenos Aires: Abeledo-Perrot, 2003.

Keynes, John Maynard. Teoría general de la ocupación, el interés, y el dinero, Eduardo Hornedo, trad. México: Editorial Muñoz S.A., 1965.

Larroulet, Cristián, y Francisco Mochón. Economía. Madrid: McGraw-Hill, 1996.

Louis Secondat, Charles, señor de la Bréde y Barón de Montesquie. El Espíritu de las Leyes, Siro García del Mazo, trad. Madrid: Librería General de Victoriano Suárez, 1906. Disponible en 〈http://fama2.us.es/fde/ocr/2006/espirituDeLasLeyesT1.pdf〉.

Maquiavelo, Nicolás. El Príncipe. Disponible en 〈http://www.ciudadoriental.com/elprincipe. pdf〉. Consulta: abril de 2016. 
Marx, Karl. El Capital. Libro primero. El proceso de producción del capital, tomo 1, volumen 3, Pedro Scaron, edit., 20a. ed. México: Siglo XXI, 2005.

Matus Benavente, Manuel. Finanzas públicas. Santiago de Chile: Editorial Jurídica de Chile, 1964.

Mijangos Borja, María de la Luz. "Conceptos generales del derecho financiero". En Beatriz Dolores Bonifaz Chapoy, dir., Panorama del derecho mexicano. Derecho financiero. México: UNAM, s. f.

Morillo-Velarde Pérez, José Ignacio. Dominio público. Madrid: Trivium, s. f.

Musgrave, Richard A., y Peggy Musgrave. Hacienda pública. Teórica y aplicada, 5a. ed., Juan Francisco Corona Ramón, Juan Carlos Costas Terrones y Amelia Díaz Álvarez, trad. Madrid: McGraw-Hill, s. f.

Nogueira Alcalá, Humberto. Teoría y dogmática de los derechos fundamentales. México: Universidad Nacional Autónoma de México, 2003. Disponible en «http://biblio.juridicas. unam.mx/libros/3/1094/4.pdf〉.

Offe, Claus. Contradicciones en el Estado de bienestar. Madrid: Alianza, 1990.

Oyarte Martínez, Rafael. Curso de Derecho constitucional, tomo I. Quito: Fundación Andrade \& Asociados Fondo Editorial, 2007.

Palomar de Miguel, Juan. Diccionario para juristas. México: Porrúa, 2012.

Pérez de Ayala, José Luis, y Eusebio González. Derecho tributario I. Salamanca: Plaza Universitaria Ediciones, 1994.

Pérez Royo, Javier. Curso de Derecho constitucional, 12a. ed. Madrid: Marcial Pons, 2010.

Queralt, Juan Martín, Carmelo Lozano Serrano, José Manuel Tejerizo López y Gabriel Casado Ollero. Curso de Derecho financiero y tributario, 17a. ed. Madrid: Tecnos, 2006.

Roldán Xopa, José. Constitución y mercado. México: Porrúa, 2004.

Rossetti, José Paschoal. Introducción a la Economía. Enfoque latinoamericano. México: Harla, Harper \& Row Latinoamericana, s. f.

Rousseau, Jean-Jacques. El contrato social o principios del derecho político, capítulo VII. Disponible en 〈http://www.biblioteca.org.ar/libros/70390.pdf〉.

Sainz de Bujanda, Fernando. Sistema de derecho financiero, volumen 1. Madrid: Facultad de la Universidad Complutense, 1985.

Samuelson, Paul, y William Nordhaus. Economía, 14a. ed. Madrid: McGraw-Hill, 1993.

Sayagués Laso, Enrique. Tratado de Derecho administrativo. Montevideo: Martín Bianchi Altuna, 1959.

Tipke, Klaus. Moral tributaria del Estado y de los contribuyentes. Madrid: Marcial Pons, 2002.

Troya Jaramillo, José Vicente. "El modelo económico, financiero y tributario de la Constitución de 2008". En Santiago Andrade, Agustín Grijalva, Claudia Storini, edit., La nueva Constitución del Ecuador. Estado, derechos e instituciones. Quito: UASB/CEN, 2009. 
Trujillo Vásquez, Julio César. "La Constitución económica, más allá del neoliberalismo". Foro: Revista de Derecho, No. 7 (2007). Disponible en 〈http://repositorio.uasb.edu.ec/ bitstream/10644/1658/1/R F-07-TC-Trujillo.pdf).

Valdés Costa, Ramón. Curso de derecho tributario, 2a. ed. Bogotá: Depalma/Temis/Marcial Pons, 1996.

Velásquez Jaramillo, Luis Guillermo. Bienes, 11a. ed. Medellín: Librería Jurídica Comlibros Ltda., 2008.

Villegas Héctor. Manual de finanzas públicas. Buenos Aires: Depalma, 2000.

Vogel, Klaus. "La Hacienda pública y el derecho constitucional". Revista Hacienda Pública Española, No. 59 (1987).

Fecha de recepción: 5 de octubre de 2016.

Fecha de aprobación: 28 de julio de 2017. 